\title{
PSICOSE E DISCURSO NO CONTEXTO DA TEORIA LACANIANA
}

Helena Veloso

Doutora em Teoria Psicanalítica pela Universidade Federal do Rio de Janeiro (UFRJ); psicanalista e professora universitária da Estácio de Sá
RESUMO: O artigo tem como tema 'as relações entre os termos discurso e psicose na teoria lacaniana. Contrariando a afirmação corrente de que na teoria de Jacques Lacan psicose e discurso seriam termos excludentes, percorre-se trechos do legado de Lacan, com o objetivo de demonstrar que as bases em que os comentadores se apoiam, em sua obra, para sustentar essa afirmação não são tão evidentes.

Palavras-chave: Psicose, discurso, Freud, Lacan.

ABSTRACT: Psychosis and discourse in the context of Lacanian theory. The topic of this article is the relationship between the terms discourse and psychosis in Lacanian theory. Contrary to the current affirmation that in the Jacques Lacan theory, psychosis and discourse are excluding terms, the author explores excerpts of Lacan's legacy, demonstrating that the bases on which the commentators hinge their work to sustain this affirmation are not so evident.

Keywords: Psychosis, discourse, Freud, Lacan.

$\mathrm{D}$ urante muito tempo, devido a uma leitura biologizada do psiquismo, a psicose foi considerada reduto da psiquiatria. Em "Notas psicanalíticas sobre um relato autobiográfico de um caso de paranoia” (FREUD, 1911/1976), a novidade introduzida por Sigmund Freud quando aborda o discurso de Schreber, tem a característica de um começo absoluto. Nesse texto pioneiro, o autor analisa a paranoia de Schreber permitindo ver que a questão posta em sua radicalidade pela psicose é a da existência de um sujeito em função de sua produção discursiva. Vemos Jacques Lacan dar continuidade ao passo inaugurado por Freud, em “Formulações sobre a causalidade 
psíquica” (LACAN, 1946/1998). Nesse texto o autor rejeita as teorias que pretendem explicar a loucura por uma perturbação das funções no interior de uma unidade orgânica ou ainda psico-orgânica para passar a atribuir a gênese dos distúrbios mentais a uma "outra forma de causalidade” (LACAN, 1946/1998, p.189), no caso, a psíquica.

Freud já havia desfeito a equivalência entre as percepções adquiridas por meio da consciência e os processos inconscientes.

“Assim como Kant nos advertiu para não desprezarmos o fato de que nossas percepções estão subjetivamente condicionadas, não devendo ser consideradas como idênticas, ao que embora o incognoscível é percebido, assim, também a psicanálise nos adverte para não estabelecermos uma equivalência entre as percepções adquiridas por meio da experiência e os processos mentais inconscientes que constituem seu objeto.” (FREUD, 1915/1976, p.197)

No texto citado,"Formulações sobre a causalidade psíquica” (1946/1998), Lacan subordina as percepções adquiridas por meio da consciência ao simbolismo, questionando uma suposta diferença existente entre a primeira e a segunda. $\mathrm{O}$ autor mostra que, por ser no simbolismo que se funda a percepção a realidade das percepções adquiridas por meio da consciência (a realidade dita externa) não pode ser considerada menos simbólica do que a resultante dos processos inconscientes (a dita interna). No debate com Henri Ey, que sustenta a tese de "uma teoria da vida psíquica incompatível com a ideia de uma psicogênese dos distúrbios mentais” (LACAN, 1946/1998, p.158), Lacan vai utilizar as considerações de Descartes sobre a loucura para mostrar que é na vida psíquica, e não na orgânica, que deve ser situada a causa destes distúrbios.

O trecho, em que o autor se apoia para explicitar os vínculos existentes entre a loucura e essa causalidade de uma ordem distinta da orgânica — que chama de psíquica - encontra-se na 'meditação primeira' do “Discurso do método para bem conduzir a própria razão e procurar a verdade nas ciências" de Descartes:

“E como é que poderei negar que estas mãos e este corpo sejam meus? Só, talvez, me comparando a certos insanos cujos cérebros estão de tal forma perturbados e ofuscados pelos negros vapores da bile que levam a afirmar a todo instante que são reis quando não passam de pobretões, que estão vestidos de ouro e púrpura quando na verdade se acham nus, ou imaginam ser um gomil e ter corpo de porcelana. Mas, ora! são loucos, e eu não seria menos extravagante do que eles se deixasse me governar por seus exemplos." (DESCARTES, 1635/1955, p.153) 
Lacan se apoia nessas considerações de Descartes sobre o comportamento dos loucos, para questionar "o que fundamenta a noção do verdadeiro na epistemologia científica” (LACAN, 1946/1998, p.154), noção que sustenta estar na base da teoria da vida psíquica em que a psicogênese se assenta. Se "refletirmos sobre o papel desempenhado pela noção de erro na concepção de Ey", asseguranos o autor, "veremos o laço que une a ilusão organicista a uma metapsicologia realista" (p.180). Lacan passa então a mostrar que, se para a psicogênese, "as doenças mentais são insultos e entraves à liberdade [...] não são causadas pela atividade livre", atividade essa que, prossegue o autor, basicamente não passa de uma "adaptação pessoal à realidade" (p.159) é porque o que "rege [...] a própria noção de verdade" (p. 165), nessa teoria, nada mais é do que o "recurso à evidência da realidade” (p.154). A partir daí todo o trabalho do autor vai ser o de tornar evidente que o que a loucura ensina é que o verdadeiro é uma noção que tem como referente menos um objeto suposto natural do que simbólico, isto é, o de desconstruir a ideia de que o verdadeiro tem como referente algo natural. É em suma, o de demonstrar, como o faz Deleuze, que "falando da condição de verdade nós nos elevamos acima do verdadeiro e do falso", que "para uma proposição ser verdadeira" nada mais é necessário "além do que a proposição" (DELEUZE, 1974, p.19), mesmo que ela designe "um estado de coisas inexistente, isto é, que não possa ser verificada diretamente" (p.15).

O conceito de verdade é utilizado por Lacan em duas acepções. No início de sua obra, o autor contrapõe o conceito de verdade definido como adequação à coisa ao conceito de verdade que podemos definir como localizada no lugar em que se a enuncia. A outra acepção em que Lacan usa esse conceito podemos encontrar mais para o final de sua obra e está relacionado ao impossível de recobrir pelo simbólico, isto é, ao real. É o primeiro uso do termo que o vemos utilizar em “Formulações sobre a causalidade psíquica” (LACAN, 1946/1998) para fazer a demonstração de que caso se parta do pressuposto da significação como condição de verdade - ou o que dá no mesmo - caso se desfaça do recurso “a evidência da realidade” (LACAN, 1946/1998, p.184) como critério para reger a noção do verdadeiro - uma teoria da vida psíquica poderá passar a comportar os fenômenos da loucura. Essa é a posição, que nesse texto, Lacan sustenta em contraposição à psicogênese.

É dessa posição que resulta a teoria alargada da vida psíquica que o autor apresenta em “Formulações sobre a causalidade psíquica” (LACAN, 1946/1998). Nela, é o próprio estatuto da verdade que é, digamos, remodelado a ponto de poder passar a incluir a verdade que o louco sustenta. Nela, “o verdadeiro está por dentro" (LACAN, 1946/1998, p.164). Nela, os que "garantem ser reis quando são muito pobres, estar vestidos de ouro e púrpura quando estão inteiramente nus" (p.158) não estão enganados ou errados, dizem a verdade. Dizem a verdade, ainda 
que essa não possa ser verificada empiricamente. Onde está o erro, se pergunta Lacan, "se o uso da fala compromete o próprio ser do objeto" (p.162)? Onde está o erro, sustenta o autor, "se uma ideia verdadeira [...] deve estar de acordo com o ideado por ela” (p.155), se há menos adaptação ao verdadeiro do que criação do verdadeiro? Assim sendo, os que garantem ser reis quando são muito pobres, estar vestidos de ouro quando estão inteiramente nus, incorrem menos em erro do que denunciam a existência de uma realidade que não possui outra garantia a não ser a da sua enunciação. Se não se trata "na anamnese psicanalítica de realidade mas de verdade" (LACAN, 1953/1998, p.257) é porque a "fala [...] constitui o sujeito em sua verdade" (LACAN, 1955/1998, p.355), “mesmo que negue a evidência, a fala constitui a verdade" (LACAN, 1953/1998, p.253).

Embora Lacan se debruce bastante a pensar, neste texto, a experiência da loucura está nela menos interessado do que em demonstrar no que essa experiência contribui, no sentido de ensinar, sobre a condição humana. E o valor que dela retira é que o que o louco testemunha é a existência de uma realidade que não se sobrepõe à dos dados imediatos da consciência. Ora, essa realidade humana, demasiadamente humana, psíquica, demasiadamente psíquica, nada mais é do que a realidade dita, não só discursiva como também constituinte de todo o humano. Por isso é que uma teoria avançada da vida psíquica requer, ou melhor, "ordena que se considere a experiência vivida antes de qualquer objetivação, e antes até de qualquer análise reflexiva que misture a objetivação com a experiência” (LACAN, 1946/1998, p.180).

Podemos afirmar que "Formulações sobre a causalidade psíquica” (LACAN, 1946/1998) é menos um texto que se atém à questão específica da loucura do que um ensaio sobre “a metafísica da condição humana” (LACAN, 1955-56/1998, p.89). A loucura encontra-se aí formulada apenas como um caso particular dessa metafísica. De que metafísica se trata? De uma metafísica que não supõe como "dado o ser do homem seja [...] como ideia, seja em sua essência como organismo” (LACAN, 1946/1998, p.162). Trata-se aí da metafísica do ‘ao que falta ser’ e seus desdobramentos. É importante assinalar que não é apenas em “Formulações sobre a causalidade psíquica” (1946/1998) que Lacan reconhece na loucura (termo que nesse texto ainda se encontra sobreposto ao da psicose) um desdobramento da metafísica da condição humana. Também no seminário III (LACAN, 1955-56/1998) o autor relacionou a falta a ser (ou esse vazio estrutural constitutivo da condição do humano) à "significação delirante” (p.41) ou ao que disse preferir nomear de “dizer psicótico” (idem). É essa metafísica que o autor tributa ser a causa de alguns efeitos, dentre eles também essa “ loucura pela qual o homem se crê homem” (Lacan,1946/1998, p.189), essa que o torna "na superfície em que nada se reflete” (p.189) cativo, “escravo [...] dessa paixão de ser" (p.189). 
Lacan vem a demonstrar que se toda loucura é vivida no registro do sentido, se ela é "um fenômeno do pensamento" (p.163), toda a realidade do humano não o é menos.

Convém assinalar, adverte-nos Lacan, que "se o homem que se acredita rei é louco, não o é menos um rei que se acredita rei” (, p.171). E o que os equivale é que, a rigor, ambos nada são. O que os equivale é que, a rigor, "o homem [...] nada [...] pode saber sobre o seu ser" (p.189). É que a constituição pela linguagem acarreta em ambos a impossibilidade de nela encontrar designação própria, representante absoluto. É que a constituição pela linguagem subordina o homem a nada mais ser do que essa metonímia significativa, esse "nó de significação” (p.167) através do qual "o não ser [...] se manifesta na ordem simbólica” (LACAN, 1954/1998, p.381). Linguagem, causa que se presentifica nos efeitos que determina.

Em “Formulações sobre a causalidade psíquica” (1946/1998), Lacan faz da loucura uma questão de sujeito, posto que é como falta a ser que o sujeito, que a psicanálise delimita, é postulado como efeito de linguagem. Por isso, a ideia de que possa não haver sujeito na loucura (termo que nesse texto encontra-se, ainda, superposto ao da psicose) encontra-se, por assim dizer, foracluída das considerações do autor sobre o tema.

A literatura psicanalítica sobre a psicose, como bem nos adverte Souza, encontra-se recheada de "afirmações intempestivas a respeito de pacientes psicóticos” (SOUZA, 1994, p.36). A própria autora relaciona algumas, tais como “o psicótico não é sujeito, não extrai o objeto a, não simboliza a castração, não tem desejo, não faz transferência” (p.36).

Como essas, encontramos outras: não tem castração, não tem conflito, não tem divisão, não faz laço social, etc. Trata-se de afirmações, prossegue a autora, que insistem em associar "psicose e déficit, psicose e deficiência” (p.36).

A autora contrapõe a atitude dos que sustentam essas afirmações à daqueles que saindo desse lugar comum, ousam querer encontrar "o que constitui positivamente a singularidade desses sujeitos" (p.36).

Basta um passar de olhos na literatura psicanalítica para verificarmos que dentre os termos ditos, supostos ou ainda tidos como negados à psicose no âmbito da teoria de Lacan, consta também o termo 'discurso'. É o que ilustra o artigo "Fora de discurso: autismo e paranoia" (SOLER, 1983) de Colette Soler, dentre outros. Nele, a autora afirma existir uma objeção ao termo 'discurso', em se tratando da psicose e do autismo, na teoria de Lacan. Segundo a autora, os psicóticos estariam na linguagem mas não chegariam a constituir um discurso devido à foraclusão do Nome-do-Pai.

A afirmação de que existe uma objeção no que tange a esse termo para a psicose, no contexto da teoria de Lacan, é frequente, tão frequente quanto aceita sem 
maiores questionamentos. Pensamos, no entanto, que a afirmação da existência dessa objeção, embora corrente (assim como tantas outras) merece ser submetida a uma análise mais séria. Como nos diz Lacan: “Uma evidência deve ser-nos tão mais suspeita quanto mais se torna uma ideia aceita” (1953/1998, p.250).

Os autores que sustentam existir tal objeção apoiam-se num texto de Lacan denominado de “L’Etourdit" (1972), mas o que nos diz o autor nesse texto permite sustentar que existe uma objeção ao termo 'discurso' para a psicose em sua teoria? Ainda que permitisse, no que essa objeção constituiria, menos um ponto pacífico do que um problema no âmbito da teoria do autor? Essas são as perguntas que balizam a tarefa que nos demos nesse trabalho, que é, em suma, a de submeter a uma análise mais rigorosa a tese de que em "L’Etourdit" Lacan teria afirmado que o psicótico está fora do discurso.

O trecho de "L’Etourdit" (LACAN, 1972) em que os comentadores se apoiam, esse em que o autor se refere à existência de um ‘fora do discurso' na psicose, não é o único em que o autor reúne os dois termos: psicose e discurso. Vale lembrar que o Seminário III - As psicoses (LACAN, 1955-56/1998) encontra-se recheado do uso do referido termo por Lacan a propósito da psicose, o que nos faz questionar o uso feito dessa afirmação feita por Lacan em “L’Etourdit”(LACAN, 1972).

É importante a ressalva de que o termo discurso já é usado por Lacan, no Seminário III (1955-56/1998), na mesma acepção em que o autor o usa em “L’Etourdit”(1972) e no "Seminário XX — Mais ainda (LACAN, 1972-73/1985). Para começar, não é como forma de expressão, meio de comunicação que o autor concebe o termo discurso, já no contexto do Seminário III (1955-56/1998), mas como constituinte da realidade humana. Se a linguagem diz respeito à existência da bateria dos significantes e seus efeitos o termo 'discurso', já nesse período da obra do autor, consiste numa estrutura que comporta uma relação determinada com o Outro e suas dimensões. É essa mesma concepção do termo discurso que encontramos na base da formulação da teoria dos quatro discursos que o autor apresenta no Seminário XVII (1969-70/1992).

Nesse contexto cada um dos discursos assume a forma de uma organização que comporta relações específicas com os elementos constituintes da estrutura. É, portanto, como laço social, ou seja, como um "modo de funcionamento" (LACAN, 1972-73/1985, p.43) uma “forma” (LACAN, 1955-56/1998, p.44) de utilização da linguagem como liame, que Lacan não apenas reconhece como admite o termo discurso para a psicose já no contexto do Seminário III (LACAN, 1955-56/1998).

Perguntamos, então, por que privilegiar uma passagem em que o autor supostamente objetaria o uso do termo 'discurso' para a psicose, em detrimento das passagens em que essa suposta objeção não estaria colocada? Por que tomar como referência uma passagem em que o autor supostamente teria situado o 
psicótico “fora do discurso" (LACAN, 1972/1973, p.71), isto é, objetado o termo discurso para a psicose, e desconsiderar as passagens em que o autor sustenta “admitir o termo discurso" (LACAN, 1955-56/1998, p.44) para as produções delirantes? O que está por trás desse recorte ou dessa escolha não seria a tendência em associar psicose e déficit, psicose e deficiência, em contraposição, tanto ao pensamento de Freud como a de Lacan que, ao "introduzir o sujeito como tal” (LACAN, 1966/1988, p. 22) ousaram, segundo as palavras do último, não apreciá-lo "em termos de déficit e de dissociação das funções" (p.22)?

Não nos parece, portanto, óbvio que os trechos em que os comentadores se apoiam para afirmar que há uma objeção ao termo 'discurso' no que tange à psicose, no contexto da teoria de Lacan, permita-os fazer tal afirmação, não porque não haja, literalmente, no contexto desse texto, a referência ao 'fora do discurso da psicose', mas porque, a nosso ver, tal afirmação não faz sentido algum se levarmos em consideração o lugar que o termo 'discurso' ocupa no contexto da teoria do autor que é o de constituinte da realidade humana.

Posto isso, ainda que os trechos em questão permitissem essa afirmação - a de que há no contexto da teoria lacaniana essa objeção ao termo discurso para a psicose - ela constituiria menos um ponto pacífico do que um problema no âmbito da teoria de um autor que parte do pressuposto de que inexiste realidade que não seja discursiva, isto é, de que "Não há nenhuma realidade pré-discursiva. Cada realidade se funda e se define por um discurso" (LACAN, 1972-73/1985, p.45). Levar em consideração o termo 'discurso', tal como Lacan o formula em sua teoria, às últimas consequências não nos obriga ao menos a questionar a suposta objeção a esse termo no que tange à psicose? No âmbito do ensino de Lacan, tirar do termo 'discurso' as verdadeiras consequências que comporta não nos impossibilitaria até mesmo de aceitar tal objeção, já que contraria os fundamentos de sua teoria, a saber, "que não há evento que não se situe a partir de um discurso” (LACAN, 1959-60b/1998, p.14), pois não há realidade fora dos significantes que a isolam? O que significa que temos que "admitir o termo do discurso" (LACAN, 1955-56/1998, p.44) também para “as produções delirantes" (p.44)?

Estranhamos, portanto, o fato de que uma objeção dessa ordem possa ser acolhida com tanta naturalidade, isto é, que possa não se constituir como uma questão para os que sustentam ou supõem sua existência no contexto do ensino desse autor. Afinal de contas, "não basta que um certo número de chaves” (LACAN, 1955-56/1998, p.88) nos tenha sido dado, como afirma Lacan, para que nos aproveitemos disso "para não pensar em mais nada, como é a inclinação geral dos seres humanos" (p.88). 


\section{SOBRE OS TRECHOS EM QUESTÃO}

Não tomando como óbvia a suposta objeção do termo 'discurso' no que tange à psicose na teoria lacaniana, na análise dos trechos de "L'Etourdit” (LACAN, 1972), nosso esforço consistirá em pensar a que esse autor pode estar se referindo quando os formula.

São dois os trechos que em "L'Etourdit” servem de apoio à tese de que Lacan teria feito uma objeção ao termo 'discurso' para a psicose. Num desses trechos a propósito da psicose, o autor afirma que o característico ao dito esquizofrênico é estar na linguagem “sans le secours d'aucun discours établi” (LACAN, 1972/1973, p.31), isto é, sem o socorro de nenhum discurso estabelecido. A mesma afirmação aparece em outro trecho, dessa vez no que diz respeito à interpretação delirante, desacompanhada do estabelecido. Nesse outro trecho, tomando da psicose emprestado o termo 'interpretação', o autor relaciona-a ao fora do discurso da psicose (p.71).

Começaremos o comentário pelo trecho que Lacan se refere à psicose para dar o exemplo de um estado que a caracteriza como 'fora do discurso'. Trata-se de um contexto em que o autor está diferenciando a psicanálise da linguística, e afirmando que o divisor de águas entre ambas é o que nomeia em sua teoria de objeto a. O objeto a, no contexto do Seminário XVII — O avesso da psicanálise (LACAN, 1969-70/1992), o autor o iguala ao "efeito de rechaço do discurso" (LACAN, 196970/1992, p.42). Trata-se de uma passagem em que o autor está falando sobre o discurso do analista e, mais especificamente, do lugar que o objeto a ocupa na estrutura desse discurso: “Disse há pouco como pode ser ocupado esse mesmo lugar dominante, quando se trata do analista. O próprio analista tem que representar aqui, de algum modo, o efeito de rechaço de discurso, ou seja, o objeto a” (p.41). O objeto a, diz o autor em outra passagem, é "queda, queda do efeito de discurso, por sua vez quebrado em algum ponto” (p.32).

Para pensarmos sobre o que Lacan pode estar dizendo quando toma a psicose para exemplificar um estado adjetivado de 'fora de discurso', resolvemos partir da pergunta: há algum estado na psicose que possa ser adjetivado de 'fora do discurso'? Não precisamos pensar muito para concluirmos que existe. Esse estado é o da loucura, nisso que, como bem nos diz Souza “é ruptura do laço social [...] nisso que ela é disruptiva” (SOUZA, 1999, p.76). Assim sendo, é possível tomar como exemplo a psicose para ilustrar uma experiência de ruptura de laço social sem que com isso estejamos afirmando a inexistência de laço social na psicose. É importante a ressalva que a experiência da loucura, da ruptura de laço social ou ainda (em proporções trágicas) de queda, quebra, rechaço de discurso, não é privilégio da psicose, neuróticos também enlouquecem. Assim como podemos situar exemplos de ruptura de laço social, de loucura, na psicose também podemos encontrá-los na neurose. O estado caracterizado por Lacan 
de ‘fora de discurso', se igualado ao de ruptura de laço social (ao da loucura), não é privativo da psicose, pois, como bem nos adverte Souza "o fenômeno, a experiência da loucura, é dado a todos" (p.78). Souza, em A psicose/um ensaio lacaniano (SOUZA, 1999) dá-nos exemplos de estados de ‘fora do discurso' ou de ruptura de laço social na neurose.

“Exemplo disto é o que a psiquiatria clássica nomeou Loucura histérica. Loucura histérica, isto é, loucura na histeria. Loucura histérica, isto é, histeria enlouquecida. Aqui se trata de um sujeito que viveu, até ali, num laço com o Outro, laço esse caracterizado por um apelo e por uma recusa simultâneos. Apelo, demanda de que o Outro dê algo, de que o Outro o faça ser alguma coisa; recusa daquilo que lhe é dado, recusa e denúncia de que isto que lhe é dado não é bem isso o que se quer. Aqui se trata de um sujeito que, por amor ao Pai — um pai ideal, idealizado, divinizado - , reduz à impotência todo aquele que se oferece como pai ou mestre. Aqui se trata de um sujeito que, sem essa referência ao pai, não poderia subsistir. E, se uma constelação de acasos ameaça e faz cair em desgraça essa função, o sujeito vê seu mundo em ruínas: o sentido já não se sustenta, os laços não mais se atam, o chão foge dos pés, tudo gira fora dos eixos. E todo um arsenal de providências, toda uma série de cuidados, se fazem necessários para que o mundo se reordene, os laços se enlacem, o sentido volte (....) a função do pai se restaure. Não só o histérico, mas também o obsessivo, tão cheio de fortalezas e armaduras, defesas e escudos, não é imune à experiência." (SOUZA, 1999, p.76)

Poder reconhecer a existência na neurose obsessiva, na histeria e na psicose desses estados de 'fora de discurso' ou de 'ruptura de laço social', não nos autoriza a concluir que a neurose obsessiva, a histeria, assim como a psicose não fazem laço social.

Não são poucos os que adjetivam de 'episódios psicóticos' as experiências de ruptura de laço social quando ocorrem no contexto da neurose. A nosso ver, nada nos autoriza também a fazer de neuróticos psicóticos, ainda que temporariamente, apenas porque enlouquecem. Se não fizermos do termo 'psicose' equivalente ao de ruptura de laço social, neuróticos poderão estabelecer e romper laços sociais (fazer a experiência da loucura) sem que por isso precisem ser adjetivados de psicóticos. Pois, diz-nos Souza, se

“o fenômeno, a experiência da loucura é dada a todos, a estrutura psicótica só é dada a alguns. A estrutura psicótica, esse constrangimento, ao mesmo tempo contingente e necessário que fixa o sujeito numa determinada posição na existência, numa determinada relação com o Outro e com o objeto, num liame particular com a verdade [...] isso é exclusivo de uns, isso é excluído a outros.” (p.78) 
É importante frisar que não estamos defendendo a tese, hoje tão comum, de que 'todo mundo delira', isto é, democratizando a psicose. Lacan faz dois usos do termo loucura em sua obra, num dos usos o equivale a psicose (nesse contexto não é louco quem quer e nem todos deliramos, já que o delírio é uma expressão da psicose) no outro uso, o diferencia da psicose fazendo da loucura um termo comum (todos podemos enlouquecer, segundo essa perspectiva). Já no contexto do Seminário III — As psicoses (LACAN, 1955-56/1998), Lacan havia distinguindo a loucura "da conduta propriamente paranoica” (LACAN, 1955-56/1998, p.26), ou seja, do tipo de organização própria à psicose:

“Não há afinal de contas, noção mais paradoxal. Se na última vez tive o cuidado de colocar a loucura no primeiro plano, é que se pode de fato dizer que, com a palavra paranoia, os autores manifestaram toda a ambiguidade presente no uso do velho termo loucura, que é o termo fundamental do comum." (p.26, grifos nossos)

Em Joyce, o sinthoma (LACAN, 1975-76), vemos esse autor afirmar que o mecanismo tributado a Joyce é a Verwerfung, isto é, que Joyce é psicótico e, ainda assim, perguntar se o mesmo é louco, retomando a diferenciação entre os dois termos.

Freud já havia começado, em sua obra, o trabalho de reunir sob um só termo os tipos clínicos que comportavam uma mesma organização de base. Foi o que o vimos fazer com a esquizofrenia e a paranoia, quando a partir da relação que ambos quadros clínicos mantêm com o traumático os condensou em uma única categoria que passou a denominar de parafrenia (FREUD, 1914/1976). A partir do conceito de narcisismo e de neuroses narcísicas esse mesmo autor já havia aproximado a melancolia da esquizofrenia e da paranoia (FREUD, 1917/1976). Lacan primou por reconhecer na psicose não um amontoado de fenômenos, mas algo, como diria o autor, a propósito do termo 'discurso', 'que subsiste em algumas relações', isto é, uma forma de amarração, um modelo de organização, em suma, uma estrutura. Lacan dá prosseguimento ao trabalho iniciado por Freud reconhecendo na psicose uma forma única de organização, e nela situando os seus subtipos, a saber, a esquizofrenia, a paranoia, a mania e a sua outra face a melancolia (LACAN, 1974/1993:44), e também o autismo. Essa estrutura é a que se caracteriza por tender a 'não função do a', como afirma Lacan no Seminário X (LACAN, 1962-63), a propósito da mania. Trata-se aí de uma estrutura que tende a se eximir de qualquer referência ao real como causa, isto é, a excluir do universo psíquico toda a referência a castração, tudo o que deixa a desejar. Desse tipo de organização resulta uma versão do Outro que Lacan descreve como consistindo num fenômeno fechado a qualquer composição dialética, como um "discurso sem descontinuidades” (Lacan, 1955-56/1992, p.142). É essa organização da 
qual resulta essa versão do Outro que Lacan reconhece também no autismo. A ponte entre o autismo e a psicose Lacan a faz quando na conferência sobre o sintoma afirma que há algo nos esquizofrênicos assim como nos autistas que gela (Lacan 1975-76a/1976), reconhecendo em ambos o caráter não dialetizável das produções que caracteriza a psicose.

Por vezes ocorre chegar as nossas mãos casos clínicos em que acreditamos nada mais ver do que a ausência de amarração dita típica à psicose. No entanto, se conseguimos prestar mais atenção, podemos fazer a feliz experiência de sermos surpreendidos.

É o caso de uma paciente que, por algum tempo, entendemos sua 'errância' como uma expressão da ausência de amarração ou de organização dita típica à psicose, isto é, como signo de ausência de um discurso. Trata-se de uma paciente que após surto, internação e encaminhamento a tratamento ambulatorial, passou a apresentar um novo comportamento, que muito preocupava seus familiares. Esse novo hábito consistia em sair de casa todos os dias e ficar literalmente vagando pelas ruas sem destino certo e expondo-se a todos os riscos que essa conduta implicava. O poder de contratualidade dessa paciente mostrou-se tão restrito, nesse momento, que apenas permitiu que os familiares conseguissem que prometesse não exercitar esse novo hábito durante as noites. No entanto, mesmo essa promessa de não sair vagando pelas ruas à noite era muito difícil de ser cumprida, pois a mesma, sempre que tinha uma oportunidade, acabava descumprindo-a. Durante um longo tempo acreditamos ver nessa atividade de vagar pelas ruas o dia inteiro um exemplo de errância, de ausência de ancoragem suposta típica à psicose. No entanto, a preocupação dos familiares e o esvaziamento das sessões era de tal forma crescente que não nos permitiu que nos acomodássemos nessa suposição, forçando-nos a interrogar a paciente sobre as razões de seu comportamento. O resultado foi o aprendizado que nos faz evocá-la neste trabalho.

Tratava-se de uma paciente em que o desencadeamento da psicose fez sua emergência numa fase tardia (em torno de seus 30 anos) e de uma forma radical, para não dizer brutal. Antes da crise, essa paciente havia-se formado em uma instituição de ensino padrão A, havia exercido sua profissão em centros de excelência de sua área, tido amigos, tido namorados, etc. Depois da crise é como se nada tivesse restado.

A crise consistiu na emergência de um novo mundo, no qual, segundo a mesma, "não existia pobreza", não existia morte, "que morte.... somos todos imortais" comunicava-me, comunicava-me essas e uma série de muitas outras coisas que deixaram de existir em seu novo mundo. Assistir à televisão tornara-se um pesadelo, diz-me a paciente, porque nela "só se fala de violência... morte... guerras... essas coisas que não existem”. Conviver com seus amigos tornara-se 
insuportável, pois eles também só sabiam, segundo a mesma, "falar dessas bobagens".

No início de seu acompanhamento ambulatorial, essa paciente revela ter preocupações com seu retorno ao trabalho, com o sumiço de seus amigos, com o abandono de seu namorado, com a miséria social, com seu futuro, etc., mas, ao longo do trabalho, essas questões pareciam não ser mais tema de preocupação. Quando a incessante atividade de vagar pelas ruas permitia-lhe vir à sessão, era para me dizer que estava tudo bem. Como havia uma relação evidente entre o esvaziamento das sessões e o aumento da atividade de vagar pelas ruas, convocála a falar sobre as razões desse comportamento tornou-se prioridade.

Não foi sem muita insistência que essa paciente veio explicar-me que o 'vagar pelas ruas' estava inserido em um novo modelo de vida por ela adotado que se resumia na palavra "independência”. Vagar pelas ruas era ficar à margem das "cobranças" de seus familiares, ficar "independente” delas. Segue-se a essa explicação a revelação de uma série de outras “independências”. Descobrira que não precisava preocupar-se com o retorno ao trabalho, poderia "viver independentemente disso também" e que não precisava de amigos, podia "ficar sozinha... em paz". Vagar pelas ruas inseria-se numa lógica de desligamentos com relação a tudo o que se colocava como problemático, a tudo o que deixava a desejar (a preocupação como o retorno ao trabalho, o incômodo de ter perdido os amigos, as expectativas de seus familiares, dentre outras). O 'vagar pelas ruas' revelou-se menos ausência de amarração do que um fenômeno resultante do modo de organização propriamente dito psicótico, a saber, o que tende a excluir do universo simbólico tudo o que deixa a desejar.

É essa forma de organização, que se caracteriza por tender a excluir tudo o que deixa a desejar do universo simbólico (ainda que seja isso o fardo da própria carne), que reconhecemos também nas palavras desse outro paciente:

- Doutora, eu não tenho ego.

- É, e como é isso?

- Numa época em que estive muito mal, eu me masturbava e ficava pensado que masturbar era uma coisa ruim, era pecado.... eu não sabia ser livre do fardo da carne.

Passemos agora à análise do outro trecho. No que tange ao trecho onde Lacan afirma que o que caracteriza o dito esquizofrênico é estar na linguagem sem o socorro de nenhum discurso estabelecido, não nos parece que o autor esteja dizendo nada que já não houvesse dito sobre a condição da psicose na linguagem desde o Seminário III (LACAN, 1955-56/1998). A tese de que a condição da psicose é estar na linguagem sem o socorro de nenhum discurso estabelecido não é nova. Ela data do Seminário III — As psicoses (1955-56/1998) e diz respeito 
ao tema da ausência de filiação. A ausência de filiação, tributada não apenas às produções esquizofrênicas, como também à interpretação delirante.

Desde o Seminário III (1955-56/1998), Lacan assinala que as produções da psicose têm por característica emergir à margem de um saber específico. Tratase do saber herdado, tradicional, transmitido. Trata-se do ordenamento comum do discurso. Data dessa época a formulação de que as produções da psicose têm como característica emergir fora desse discurso. Assim, tanto a posição do sujeito na esquizofrenia, como a "posição do sujeito [...] na paranoia” (LACAN, 195960/1998, p.584). compartilhariam, como afirma Lacan a propósito da paranoia, “dessa rejeição de um certo apoio da ordem simbólica” (p.584). Essa falta de apoio na ordem simbólica, o autor a relaciona à Verwerfung do Nome-do-Pai.

"de que se trata quando falo da Verwefung? Trata-se da rejeição de um significante primordial $[\ldots]$ trata-se de um processo primordial de exclusão [...] de um primeiro corpo de significantes [...] do mundo da realidade já pontuado, já estruturado." (LACAN, 1955-56/1998, p.174)

Estabelecido? Sim, responderíamos com Lacan, trata-se de um "nó, um ponto de aperto, um feixe de significações adquiridas ou não pelo sujeito” (idem, p.316).

“Para saber [...] o que dizemos quando dizemos por exemplo que na psicose algo vem a faltar na relação do sujeito com a realidade, trata-se com efeito da realidade estruturada pela presença de um certo significante que é herdado, tradicional, transmitido." (idem, p.283)

É por causa da despossessão primitiva dessas “justas medidas que [...] chamam de [...] realidade humana”(p.283), da despossessão dessa “estrada principal”(p.283), que os psicóticos se vêm “diante de um certo número de pequenos caminhos elementares”(p.283), pois “quando não há estrada principal”(p.283), prossegue o autor, os que a rejeitam “seguem letreiros postos a beira dessa estrada" (p.283).

É da despossessão desse significante que emerge a produção propriamente dita psicótica. Para os despossuídos do saber suposto do pai como herança, para os que ousaram foracluir "o significante [...] pai" (p.283), rejeitar a impostura paterna, diz Lacan, “a realidade [...] não está assegurada, contrariamente ao sujeito normal para quem a realidade lhe chega de bandeja [...] aquilo que se trata $[\ldots]$ da alucinação a interpretação [...] lhe concerne" (p.91).

Se adotarmos essa perspectiva, o fora do discurso da psicose em "L’Etourdit" (1972) não é uma afirmação absoluta, mas relativa a esse discurso particular 
que é o estabelecido, ou ainda, a esse estado particular que é o da loucura. É essa a perspectiva que nos permite questionar as bases em que os comentadores se apoiam, no contexto do ensino de Lacan, para caracterizar a psicose como deficitária, também, de um discurso.

Recebido em 15/7/2007. Aprovado em 14/4/2008.

\section{REFERÊNCIASS}

DELEUZE, G. (1974) Lógica do sentido. São Paulo: Perspectiva.

DESCARTES, R. (1635/1955) “Discurso do método para bem conduzir a própria razão e procurar a verdade nas ciências”, in VALÉRY, P. O pensamento vivo de Descartes. São Paulo: Martins Fontes.

FREUD, S. (1976) Edição standard brasileira das obras completas. Rio de Janeiro: Imago.

(1911) "Notas psicanalíticas sobre um relato autobiográfico de um caso de paranoia”, v.XII, p.15-108.

(1914) "Sobre o narcisismo: uma introdução", v.XIV, p.84-119.

(1915) “O inconsciente”, v.XIV, p.185-239.

(1917) “Luto e melancolia”v.XIV, p.270-294.

LACAN, J. (1946/1998) “Formulações sobre a causalidade psíquica”, in Escritos. Rio de Janeiro: Zahar. (1953/1998) "Função e campo da fala e da linguagem em psicanálise”, in Escritos. Rio de Janeiro: Zahar.

(1954/1998) "Introdução ao comentário de Jean Hyppolite sobre a 'Verneinung' de Freud”, in Escritos. Rio de Janeiro: Zahar. . (1955/1998) "Variantes do tratamento padrão”, in Escritos. Rio de Janeiro: Zahar. Zahar.

.(1955-56/1998) O Seminário livro 3, As psicoses. Rio de Janeiro:

(1959-60/1998) "Observação sobre o relatório de Daniel Lagache: Psicanálise e estrutura da personalidade”, in Escritos. Rio de Janeiro: Zahar.

.(1959-60b/1992) "Resenha da ética", in Falo - Revista brasileira do campo freudiano, n.2/3. Salvador: Fator.

. (1962-63) L’angoisse. (Seminário inédito).

(1966/1998) “A ciência e a verdade”, in Escritos. Rio de Janeiro: Zahar.

.(1969-70/1992) O Seminário livro 17, O avesso da psicanálise. Rio de Janeiro: Jorge Zahar.

. (1972/1973) L’Étourdit, Scilicet, n.4. Paris: Seuil.

(1972-73/1985) O Seminário livro 20, Mais ainda. Rio de Janeiro:

Zahar. 
(1974/1993) Televisão, Rio de Janeiro: Zahar.

(1975-76a/1976) Le Sinthome, Ornicar? bulletin périodique do champ freudien. Paris:Lyse.

(1975-76) Le Sinthome (seminário inédito).

SOLER, C. (1990) Fora do discurso: autismo e paranoia, Feuilletes de courtil n.2, Bruxelas: Courtil.

SOUZA, N. S.A. (1994) Transferência e direção da cura na psicose, Pulsional, n.57. São Paulo: Livraria pulsional, p.36-43.

(1999) Psicose: um estudo lacaniano. Rio de Janeiro: Revinter.

Helena Veloso

helenaveloso@hotmail.com 